\title{
Sikap dan Praktik Pemberian Susu Formula pada Bayi Usia 6 Bulan sampai dengan 2 Tahun
}

\author{
Hilda Yani Karo Karo ${ }^{1^{*}}$, Norliana Karo Karo ${ }^{2}$ \\ $1^{*}, 2$ Program Studi Sarjana Kebidanan Universitas Audi Indonesia, Kota Medan, Sumatera Utara, Indonesia \\ *corresponding author \\ Hilda Yani Karo Karo \\ JI. Bunga N'Cole Raya No.83 Medan Tungtungan, Sumatera Utara, Indonesia (20136) \\ Hildayanie354@gmail.com
}

\begin{abstract}
Abstrak
Perkembangan gaya hidup dan pola pemberian nutrisi pada anak terus berkembang sejalan dengan perkembangan zaman. Salah satu pola pemberian nutrisi tersebut adalah pemberian susu formula atau non air susu ibu yang digemari sebagian orang tua. Sebenarnya, jika dilihat dari sisi kesehatan, pemberian susu formula tidak lebih dari ASI. Hal itu dikarenakan susu instan atau susu formula mengandung gula tambahan. Bayi yang mengkonsumsi susu formula lebih besar kemungkinan untuk mengalami diare, infeksi saluran nafas, obesitas dan penyakit diabetes di kemudian hari daripada bayi yang mengkonsumsi ASI. Jenis penelitian ini adalah bersifat deskriptif dengan pendekatan cross sectional yaitu data yang dikumpulkan pada saat itu juga yang bertujuan untuk mengetahui perilaku ibu terhadap pemberian susu formula pada usia 6 bulan sampai dengan 2 tahun di Klinik Wifa Medan. Populasi dalam penelitian ini adalah ibu yang datang ke Klinik Wifa Medan yang memberikan susu formula pada usia 6 bulan sampai dengan 2 tahun sebanyak 30 orang. Pengambilan sampel dengan menggunakan Accidental sampling. Hasil penelitian diperoleh bahwa pengetahuan ibu yang berpengetahuan baik sebanyak 9 orang $(30 \%)$, berpengetahuan cukup 15 orang $(50 \%)$, dan berpengetahuan kurang sebanyak 6 orang (20\%). Mayoritas ibu yang memberikan susu formula pada usia 6 bulan sampai dengan 2 tahun memiliki sikap positif sebanyak 11 orang $(36,67 \%)$ dan sebagian memiliki sikap negatif sebanyak 19 orang $(63,33 \%)$.
\end{abstract}

Kata kunci: Sikap; Praktik; Bayi; Susu Formula; Usia 6 Bulan sampai dengan 2 Tahun

\section{Attitudes and Practices of Formula Milk Giving for Infants Aged 6 Months to 2 Years}

\begin{abstract}
Lifestyle development and patterns of providing nutrition to children continue to develop in line with the times. One of the patterns of providing these nutrients is formula milk or nonbreast milk which is favored by some parents. Actually, when viewed from the side of health, formula milk is no more than breast milk. That is because instant milk or formula milk contains added sugar. Babies who consume formula milk are more likely to experience diarrhea, respiratory infections, obesity and diabetes later in life than babies who consume breast milk. This type of research is descriptive with cross sectional approach, namely data collected at that time which aims to determine the behavior of mothers towards formula feeding at the age of 6 months to 2 years at the Wifa clinic in Medan. The population in this study were mothers who came to the Wifa Medan clinic who provided formula milk at the
\end{abstract}


age of 6 months to 2 years as many as 30 people. Sampling using Accidental sampling. The results showed that knowledge of mothers who are well-knowledgeed are 9 people (30\%), have enough knowledge of 15 people (50\%), and lack knowledge of 6 people (20\%). The majority of mothers who give formula milk at the age of 6 months to 2 years have a positive attitude of 11 people (36.67\%) and some have a negative attitude of 19 people (63.33\%).

\section{Keyword: Attitude; Practice; Infant; Formula Milk; Age 6 Months to 2 Years}

\section{Pendahuluan}

Perkembangan gaya hidup dan pola pemberian nutrisi pada anak terus berkembang sejalan dengan perkembangan zaman. Salah satu pola pemberian nutrisi tersebut adalah pemberian susu formula atau non air susu ibu yang digemari sebagian orang tua. Sebenarnya, jika dilihat dari sisi kesehatan, pemberian susu formula tidak lebih dari ASI. Hal itu dikarenakan susu instan atau susu formula mengandung gula tambahan (Lakshita, 2012). United Nations Internasional Children Emergency Fund menyatakan Indonesia menjadi salah satu pasar utama dalam pemasaran produk susu formula. Menurut laporan, angka penjualan susu formula di dunia meningkat sebesar 37 persen pada tahun 20082013.

Hampir semua rumah sakit yang dikunjungi memberikan susu botol pada hari pertama bayi lahir, menyebabkan risiko bayi mengalami sakit pasti bertambah, karena susu formula tidak se-steril yang di perkiraan, susu bisa terkontaminasi saat di pabrik, isi kehigienisan perlengkapan seperti, botol, dot, dan akses ke air bersih yang dibutuhkan untuk membuat susu formula.

Bayi yang mengkonsumsi susu formula lebih besar kemungkinan untuk mengalami diare, infeksi saluran nafas, obesitas dan penyakit diabetes di kemudian hari daripada bayi yang mengkonsumsi ASI (Sudilarsih, 2009). Data Riset Kesehatan Dasar (Riskesdas) tahun 2010 menunjukkan pemberian ASI di Indonesia saat ini memprihatinkan, persentase bayi yang menyusu eksklusif sampai 6 bulan hanya 15,3\%. Karena pemberian makanan prelaktal yang paling banyak diberikan adalah susu formula $(71,3 \%)$. Makanan prelaktal berupa susu formula lebih tinggi di perkotaan (82,3\%) daripada di pedesaan (59,8\%). Kemudian pemberian makanan prelaktal di Provinsi Sumatera Utara sebanyak $73,5 \%$. Hal ini disebabkan kesadaran 
masyarakat dalam mendorong peningkatan pemberian ASI masih relatif rendah.

Sayangnya sikap dan praktik yang baik memberikan ASI eksklusif kepada bayi sendiri dianggap sebagian orang suatu tingkah laku yang tradisional, sehingga sedikit demi sedikit ditinggalkan, hal tersebut dipengaruhi oleh kemajuan di Negara industri yang memperkenalkan susu buatan untuk bayi dan mempunyai manfaat yang sama dengan ASI eksklusif, pemakaian lebih praktis dengan promosi pemasaran susu buatan atau makanan pengganti asi secara gencar (Depkes RI, 2000).

Berdasarkan latar belakang di atas peneliti tertarik untuk mengambil judul tentang "Sikap dan Praktik Pemberian Susu Formula pada Bayi Usia 6 bulan sampai dengan 2 Tahun".

\section{Metode}

Desain penelitian ini bersifat deskriptif dengan pendekatan cross sectional yaitu data yang dikumpulkan pada saat itu juga yang bertujuan untuk mengetahui perilaku ibu terhadap pemberian susu formula pada usia 6 bulan sampai dengan 2 tahun di Klinik Wifa Medan. Populasi dalam penelitian ini adalah yang datang di Klinik Wifa Medan yang memberikan susu formula pada usia 6 bulan sampai dengan 2 tahun sebanyak 30 orang. Pengambilan sampel dengan menggunakan Accidental sampling.

\section{Hasil}

Berdasarkan hasil kuesioner responden yang lebih banyak menjawab benar sebanyak 24 Orang $(80 \%)$ dengan pertanyaan "Menurut ibu, bagaimana cara penyimpanan susu formula yang baik", dan yang lebih banyak menjawab salah sebanyak 21 orang $(70 \%)$ dengan pertanyaan "Apa hal pertama yang dilakukan ibu sebelum memberikan bayi susu formula dengan menggunakan botol dot".

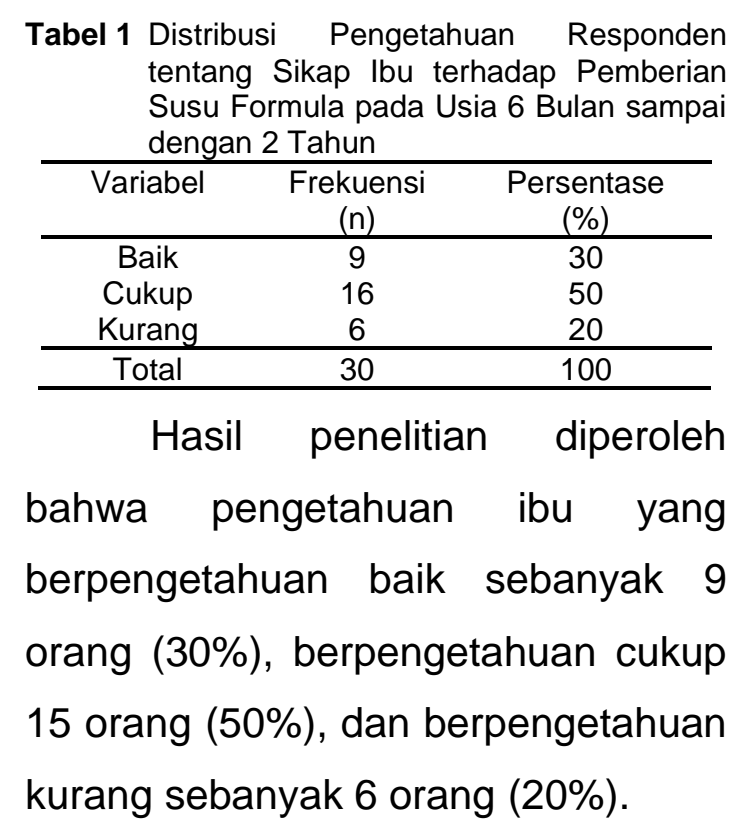

Tabel 1 Distribusi Pengetahuan Responden tentang Sikap lbu terhadap Pemberian Susu Formula pada Usia 6 Bulan sampai dengan 2 Tahun

bahwa pengetahuan ibu yang berpengetahuan baik sebanyak 9 orang (30\%), berpengetahuan cukup kurang sebanyak 6 orang (20\%). 
Berdasarkan hasil pilihan jawaban sikap ibu pada kuesioner didapatkan bahwa responden yang mayoritas menjawab pertanyaan sangat setuju tentang memeriksa suhu susu pada tangan sebelum memberikan susu pada bayi sebanyak 12 orang $(40 \%)$, responden yang mayoritas menjawab pertanyaan setuju mencuci botol bekas susu harus dilakukan sebanyak 17 orang $(56,7 \%)$, sedangkan responden yang menjawab pertanyaan tidak setuju memberi susu formula mengurangi hubungan kasih sayang ibu dan anak sebanyak 19 orang $(63,3 \%)$.

Tabel 2 Distribusi Frekuensi Sikap Responden terhadap Pemberian Susu Formula

\begin{tabular}{ccc}
\hline Variabel & $\begin{array}{c}\text { Frekuensi } \\
(\mathrm{n})\end{array}$ & $\begin{array}{c}\text { Persentase } \\
(\%)\end{array}$ \\
\hline Positif & 11 & 36,67 \\
Negatif & 19 & 63,33 \\
\hline Total & 30 & 100 \\
\hline
\end{tabular}

Distribusi frekuensi berdasarkan sikap ibu dari 30 responden sebagian memiliki sikap positif sebanyak 11 orang $(36,67 \%)$ terhadap pemberian susu formula pada bayi usia 6 bulan sampai dengan 2 tahun dan sikap negatif sebanyak 19 orang (63,33\%) terhadap pemberian susu formula.

Distribusi berdasarkan praktik hasil pilihan jawaban kuesioner ibu didapat bahwa responden yang mayoritas menjawab pertanyaan tentang jika bayi mengalami diare ibu pergi ke petugas kesehatan sebanyak 26 orang $(86,7 \%)$, kemudian didapat responden yang menjawab tidak dipraktikkan tentang selesai memberi susu pada bayi apa ibu langsung mencuci botol susunya sebanyak 20 orang $(66,7 \%)$.

Distribusi frekuensi berdasarkan keseluruhan tindakan responden tentang perilaku ibu terhadap pemberian susu formula pada usia 6 bulan sampai dengan 2 tahun adalah sebagai berikut:

Tabel 3 Distribusi Frekuensi Berdasarkan Praktik Responden terhadap Pemberian Susu Formula pada Usia 6 bulan sampai dengan 2 tahun

\begin{tabular}{ccc}
\hline Variabel & $\begin{array}{c}\text { Frekuensi } \\
(\mathrm{n})\end{array}$ & $\begin{array}{c}\text { Persentase } \\
(\%)\end{array}$ \\
\hline Baik & 13 & 43,33 \\
Tidak Baik & 17 & 56,67 \\
\hline Total & 30 & 100 \\
\hline \multicolumn{2}{c}{ Distribusi } & frekuensi
\end{tabular}
berdasarkan praktik responden diperoleh praktik baik sebanyak 13 orang $(43,33 \%)$ terhadap pemberian susu formula dan praktik tidak baik sebanyak 17 orang $(56,67 \%)$ terhadap pemberian susu formula.

\section{Pembahasan}

Pembahasan hasil penelitian disajikan dengan mengacu pada tujuan penelitian ini yaitu untuk mengidentifikasi pengetahuan, sikap dan tindakan ibu terhadap pemberian susu formula pada usia 6 bulan 
sampai dengan 2 tahun di Klinik Wifa sebagai berikut:

\section{Pengetahuan lbu terhadap} Pemberian Susu Formula pada Usia 6 Bulan sampai dengan 2 Tahun di Klinik Wifa

Tabel 1 dapat diamati bahwa pengetahuan ibu terhadap pemberian susu formula pada usia 6 bulan sampai dengan 2 tahun mayoritas berpengetahuan baik sebanyak 9 orang (30\%), berpengetahuan cukup sebanyak 15 orang (50\%), dan sebagian kecil berpengetahuan kurang sebanyak 6 orang (20\%).

Hal ini menyatakan bahwa ibu yang memberikan susu formula yang memiliki tingkat pengetahuan baik berarti sudah memperoleh informasi tentang cara pemberian susu formula yang baik dari berbagai sumber seperti media elektronik, media massa, keluarga, ataupun dari petugas kesehatan. Sedangkan ibu yang memberikan susu formula yang memiliki tingkat pengetahuan kurang disebabkan oleh kurangnya informasi dan wawasan ibu yang diperoleh baik dari media elektronik, keluarga, media massa, maupun dari petugas kesehatan
Sikap Ibu terhadap Pemberian Susu Formula pada Usia 6 Bulan sampai dengan 2 Tahun di Klinik Wifa

Tabel 2 diperoleh data mayoritas ibu yang memberikan susu formula pada usia 6 bulan sampai dengan 2 tahun memiliki sikap positif sebanyak 11 orang $(36,67 \%)$ dan sebagian memiliki sikap negatif sebanyak 19 orang $(63,33 \%)$.

Hal ini menunjukkan bahwa ibu yang memberikan susu formula yang memiliki sikap positif karena didukung oleh pengetahuan yang baik terhadap cara pemberian susu formula yang benar. Sedangkan ibu yang memberikan susu formula yang memiliki sikap negatif karena tidak didukung dengan pengetahuan yang baik mengenai cara pemberian susu formula yang benar.

Sikap baik dan cukup dapat dipengaruhi oleh pengalaman langsung yang dialami individu terhadap sesuatu hal dan sikap tidak dibawa sejak lahir tetapi dipelajari dan dibentuk berdasarkan pengalaman individu sepanjang perjalan perkembangan selama hidupnya. Sikap tidak lepas dari pengaruh interaksi manusia satu dengan yang lain. 
Tindakan Ibu terhadap Pemberian Susu Formula pada Usia 6 Bulan sampai dengan 2 Tahun di Klinik Wifa

Tabel 3 diperoleh mayoritas ibu yang memberikan susu formula pada usia 6 bulan sampai dengan 2 tahun memiliki tindakan baik sebanyak 13 orang $(43,33 \%)$, dan tindakan tidak baik sebanyak 17 orang (56,67\%).

Hal ini menunjukkan bahwa ibu yang memiliki sikap tindakan baik berarti ibu mengerti pemberian susu formula yang benar, dan yang memiliki tindakan tidak baik ibu tidak mengerti cara pemberian susu formula yang benar.

Menurut Notoatmodjo (2007), tindakan atau dilaksanakan setelah seseorang mengetahui stimulus atau objek kemudian mengadakan penilaian terhadap apa yang diketahui. Dengan kata lain tindakan atau praktik dilaksanakan karena dinilai baik dan diyakini.

\section{Simpulan}

Pengetahuan responden terhadap pemberian susu formula pada usia 6 bulan sampai dengan 2 tahun, mayoritas mempunyai pengetahuan cukup sebanyak 15 orang $(50 \%)$.
Sikap responden terhadap pemberian susu formula pada usia 6 bulan sampai 2 tahun, mayoritas memiliki sikap negatif sebanyak 19 orang $(63,33)$.

Praktik responden pemberian susu formula pada usia 6 bulan sampai dengan 2 tahun, mayoritas mempunyai tindakan tidak baik sebanyak 17 orang (56,67\%).

Saran

Kepada petugas kesehatan di rumah bersalin agar memberi pendidikan kesehatan yaitu berupa mengajarkan kepada para ibu dalam pemberian susu formula yang benar pada usia 6 bulan sampai 2 tahun .

Bagi para ibu diharapkan dapat melakukan pemberian susu formula yang benar pada usia 6 bulan sampai 2 tahun.

Bagi peneliti selanjutnya diharapkan agar dapat melakukan penelitian ini ditempat lain dengan jumlah sampel yang lebih banyak. Karena pada penelitian ini peneliti mengalami keterbatasan terhadap sampel.

\section{Daftar Pustaka}

BKKBN. (2004). ASI Eksklusif Turunkan Kematian Bayi .http://www.pikas.bkkbn.go.id/pri 
nt.php?tid+2\&rid=136-6k-sp $\quad$ (3 September 2009)

Chantry C.J., Howard C.R., Auinger P. (2006). Full breastfeeding duration adn assiciated decrease in respiratory tract infection in US children. Pediatrics 117 (2) : 425431.

Dahlan, M. Sopiyudin (2006). Statistika untuk kedokteran dan kesehatan : uji hipotesis dengan menggunakan SPSS ( seri evidence based medicine 1).Jakarta : Arkans, p:

Depkes. (2001). Strategi Nasional Peningkatan Pemberian ASI tahun 2001-2005. Makalah disampaikan pada Workshop Peningkatan Pemberian ASI. Jakarta .

Hasan, R. dan Alatas, H. (ed). (2010) .Buku Kuliah IImu Kesehatan Anak I.cet.ke:8. Bagian IImu Kesehatan Anak Fakultas Kedokteran Universitas Indonesia. Jakarta.

Hendarto A. dan Pringgadini K. (2008). Nilai Nutrisi Air Susu Ibu. In : IDAI. Bedah ASI : Kajian dari Berbagai Sudut Pandang IImiah. Jakarta : Balai Penerbit FKUI, p: 46.

Krisnatuti D. dan Yenrina R. (2000). Menyiapkan Makanan Pendamping ASI.http://hidayat2.wordpress.co m/2010/01/10/jurnal-01/ September 2009)

Markum, A.H., (2002). Buku Ajar IImu Kesehatan Anak. Jilid 1. Jakarta: FKUI, p: 24.

Masri, S.H. (2004). Diare Penyebab Kematian 4 Juta Balita Per Tahun.

http://www.waspada.co.id/serbaserbi/kesehatan/artikel.,php?arti kel-id=61175-35k(2 September 2009)

Matondang C.S., Munatsir Z., Sumadiono. (2008). Aspek Imunologi Air Susu Ibu. In : Akib A.A.P.,

Munasir Z., Kurniati N (eds). Buku Ajar Alergi-Imunologi Anak, Edisi II. Jakarta : Badan Penerbit IDAI, pp: 189-202.

Moehji S. (2010). Ilmu Gizi 2. Jakarta: Penerbit Papas Sinar Sinanti, pp: 78-90

Munasir Z. dan Kurniati N. (2008). Air Susu Ibu dan Kekebalan Tubuh. In : IDAI. Bedah ASI : Kajian dari Berbagai Sudut Pandang IImiah. Jakarta : Balai Penerbit FKUI, pp: $69-79.30$ 